2013-3

\title{
The Effects of Physical Activity on Greenhouse Gas Emissions for Common Transport Modes in European Countries
}

Aidan Duffy

Technological University Dublin, aidan.duffy@tudublin.ie

Robert Crawford

University of Melbourne, rhcr@unimelb.edu.au

Follow this and additional works at: https://arrow.tudublin.ie/dubenart

Part of the Energy Systems Commons, Environmental Engineering Commons, and the Environmental Indicators and Impact Assessment Commons

\section{Recommended Citation}

Duffy, A. \& Crawford, R. (2013) The effects of physical activity on greenhouse gas emissions for common transport modes in European countries. Transportation Research Part D: Transport and Environment, vol. 19, March 2013, pp. 13-19. doi:10.1016/j.trd.2012.09.005.

This Article is brought to you for free and open access by the Dublin Energy Lab at ARROW@TU Dublin. It has been accepted for inclusion in Articles by an authorized administrator of ARROW@TU Dublin. For more information, please contact arrow.admin@tudublin.ie, aisling.coyne@tudublin.ie,gerard.connolly@tudublin.ie.

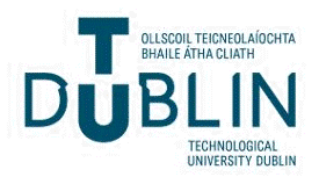




\section{AUTHOR QUERY FORM}

\begin{tabular}{|l|l|l|}
\hline & Please e-mail or fax your responses and any corrections to: \\
$\begin{array}{l}\text { E-mail: corrections.esch@elsevier.sps.co.in } \\
\text { ELSEVIER }\end{array}$ & Article Number: 782 & Fax: $+\mathbf{3 1} 204852799$ \\
\hline
\end{tabular}

Dear Author,

Please check your proof carefully and mark all corrections at the appropriate place in the proof (e.g., by using on-screen annotation in the PDF file) or compile them in a separate list. Note: if you opt to annotate the file with software other than Adobe Reader then please also highlight the appropriate place in the PDF file. To ensure fast publication of your paper please return your corrections within 48 hours.

For correction or revision of any artwork, please consult http://www.elsevier.com/artworkinstructions.

Any queries or remarks that have arisen during the processing of your manuscript are listed below and highlighted by flags in the proof. Click on the ' $\mathrm{Q}$ ' link to go to the location in the proof.

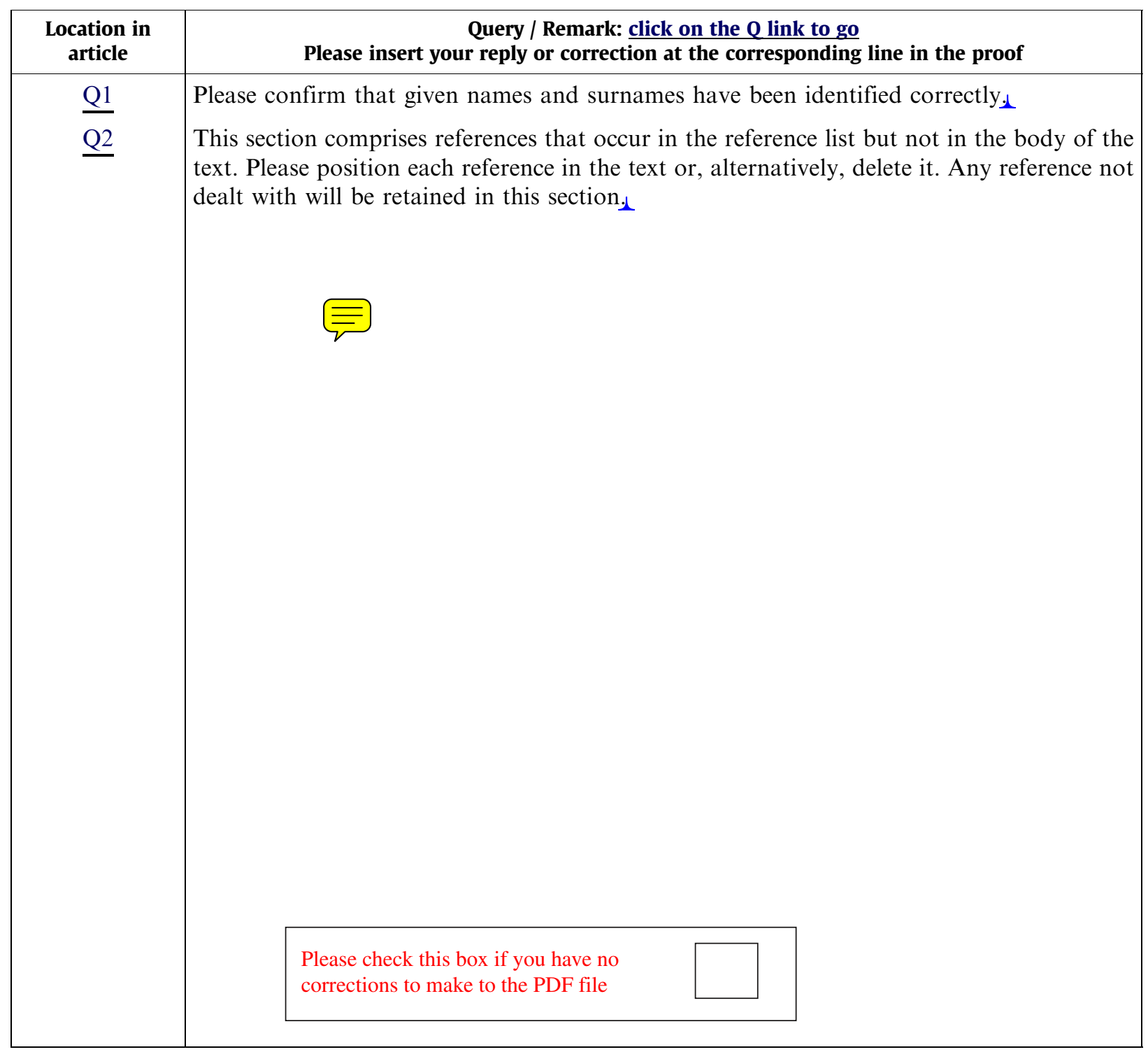




\section{Highlights}

A method to estimate activity-related emissions for transport modes is developed. The method is internationally applicable. Food energy-related emissions for walking, cycling and driving are presented. Life cycle emissions are estimated for car and bus travel, cycling and walking. 


\section{The effects of physical activity on greenhouse gas emissions for common transport modes in European countries}

${ }^{a}$ School of Civil, Structural and Environmental Engineering and Dublin Energy Lab, Dublin Institute of Technology, Bolton Street, Dublin, Ireland

${ }^{\mathrm{b}}$ Faculty of Architecture, Building and Planning, The University of Melbourne, Parkville, Victoria 3010, Australia

\section{A R T I C L E I N F O}

\section{Keywords:}

Transport emissions

Life cycle assessment

Carbon accounting

Greenhouse gas emissions

\begin{abstract}
A B S T R A C T
This paper applies a life cycle methodology to estimate activity-related contributions of transport modes to GHG emissions. The methodology uses national input-output tables, environmental accounts, household budget data and nutritional data to derive food-sector GHG coefficients of consumption for ten European countries. The food energy requirements for each mode of transport are estimated taking account of the modal activity level and energy requirements. Typical national food energy-related emissions for walking, cycling, and driving ranged from 25.6 to $77.3 \mathrm{gCO}_{2}$-eq/pass.km, $10.4-31.4 \mathrm{gCO}_{2}$-eq/pass.km and 1.7-5.2 $\mathrm{gCO}_{2}$-eq/pass.km; $\mathrm{pa}_{2}$ Emissions vary between countries depending on the emissions intensities of their energy sectors as well as food prices and average body weights. A life cycle assessment of modal emissions in the UK is undertaken using the food-energy emissions intensities estimated and car travel was found to have the highest emissions intensity, followed by bus, cycling and walking.
\end{abstract}

(c) 2012 Elsevier Ltd. All rights reserved.

\section{Introduction}

A variety of methodological approaches to modelling emissions from transport systems exist and include 'top down' and 'bottom up' methods with an assessment of the life cycle aspects and impacts of transport projects or policies is now generally considered best practice. Although direct fuel-related greenhouse gas (GHG) emissions dominate some transport modes, other indirect life cycle components relating to vehicle manufacture, maintenance and the provision of infrastructure also contribute significantly. A simplistic analysis would conclude that neither cycling nor walking uses fossil fuels since food energy is used as a means of propulsion; similarly, manufacturing and maintenance impacts would appear to be low. This is incorrect because the production of food results in GHG emissions associated with methane emissions, the direct use of fossil-fueled machinery and the indirect emissions associated with the provision of products and services to the agrifood industry. Therefore, cycling and walking, which result in increased metabolic rates, require greater food energy consumption and resultant GHG emissions.

Estimates of active transport emission factors vary significantly; for example Chapman (2007) and Santos et al. (2010) report zero emissions, while Walsh et al. (2008) finds emissions intensities of 11, 29 and $149 \mathrm{gCO}_{2} /$ pass.km for cycling, electric rapid rail and private car. Respired $\mathrm{CO}_{2}$, however, does not add to naturally-occurring concentrations since it forms part of the natural, closed $\mathrm{CO}_{2}$ cycle. Coley (2002) correctly ignores bio-chemical emissions and, using indirect embodied energy values reported in van Engelenburg et al. (1994) and data from a survey of UK adult diets, estimates emissions equivalent to 41.80 and $30.43 \mathrm{gCO}_{2} /$ pass.km for walking and cycling. The analysis, however, mixed Dutch food energy intensities with UK

\footnotetext{
* Corresponding author.

E-mail address: aidan.duffy@dit.ie (A. Duffy).
} 
food consumption and employed an aggregated economy-wide $\mathrm{CO}_{2}$ emission factor to estimate modal emissions. Here we develop a life cycle methodology for estimating the activity-related contributions of transport modes to GHG emissions.

\section{Methodology}

Metabolic equivalent (MET) can be defined as the ratio of the work metabolic rate (the rate of energy expenditure whilst undertaking dn activity) to the resting metabolic rate (RMR) (the rate of energy expenditure while resting), where a MET of one is approximately equivalent to sitting quietly (Ainsworth et al., 2011). RMR has been found to be dependent on gender, age, overall body size and, most importantly, on body mass (McArdle et al., 2007); for example, values for adult males may vary from 0.8 to $1.7 \mathrm{kcal} / \mathrm{min}$ (Longo et al., 2011). Physical exercise has a significant impact on energy expenditure, with most humans able to increase their MET by an order of magnitude during large muscle exercise, although under normal circumstances physical activity accounts for $15-30 \%$ of a person's daily energy expenditure.

Traditionally, food energy is measured in large calories (Cal), which are equivalent to kilocalories (kcal). Although the SI unit is kilojoules (kJ), where $1 \mathrm{kcal}$ is equivalent to $4.1868 \mathrm{~kJ}$, the energy content of food is still widely expressed in Cals or kcals.

The production of food results in GHG emissions from a number of processes including:

- the transformation of fossil fuels into energy used for agricultural activities, food transportation and processing, resulting in the release of GHGs, predominantly $\mathrm{CO}_{2}$;

- deforestation resulting both in the release of $\mathrm{CO}_{2}$ and other GHGs during decay or burning of waste biomass and the reduced capacity to sequester $\mathrm{CO}_{2}$; and

- the production of other GHGs such as methane from livestock.

Each GHG has an effect on global warming; its global warming potential (GWP). GWPs are measured using a normalised scale where a GWP of 1 is equivalent to the warming effect of $\mathrm{CO}_{2}$. Where an environmental aspect involves a number of GHG gases, their emissions-weighted GWPs can be summed to give a carbon dioxide equivalent $\left(\mathrm{CO}_{2}\right.$-eq). All emissions are reported in $\mathrm{CO}_{2}$-eq for a 100 -year time horizon based on Forster et al. (2007).

GHG emissions may be either direct or indirect. The former are a result of activities at the particular stage of the life cycle in question. For example, direct emissions from a car include the fuel used, but exclude emissions from upstream or downstream stages such as car maintenance or manufacture which are indirect emissions. To reflect direct and indirect effects we make use of input-output (IO) analysis combined with process analysis. The latter involves identifying the supply chain upstream of a product or service, measuring and summing the emissions for all direct and indirect activities. These data are combined with material quantities to give emissions for a particular product or service. IO analysis is complete when applied to sectors where the product/service can be treated homogenously but when individual products/services are analysed, process analysis can be applied where system boundaries are limited and data applicable; for more complete boundaries, an appropriate hybrid approach is needed.

An IO approach is used to determine modal emissions intensities because the analysis relates to a 'person' of average weight in a country, with a representative diet and an average metabolism and because the overall impact on national emissions is desired, specific products or services need not be considered. The ten EU countries studied reflect data availability; they are Austria (AT), Denmark (DK), France (FR), Germany (DE), Italy (IT), Netherlands (NL), Portugal (PT), Spain (ES), Sweden (SE) and the UK. The base year is 1999 due to the use of the Eurostat Household Budget Survey (HBS) for calculating food energy intensities, which was last released for that year. Where necessary, price adjustments to 1999 levels were undertaken using data from Organisation for Economic Cooperation and Development (2001).

We use aggregate national sector IO tables to be compatible with the sectors reported in national environmental accounts and deriving the food-sector GHG coefficients of consumption. The food energy in each unit of expenditure was calculated based on the per capita cost of food and calorie intakes in each country. The food-energy emissions intensity of each mode is given by the product of $f_{2}$ the food-sector GHG coefficient of consumption; the food energy in each unit of expenditure; and modal food energy requirements.

Country-specific sector $\mathrm{GHG}$ emissions $\left(\mathrm{CO}_{2}, \mathrm{CH}_{4}\right.$, and $\left.\mathrm{N}_{2} \mathrm{O}\right)$ for 1999 are obtained from Eurostat, converted to $\mathrm{CO}_{2}$-eq and aggregated to match NACE economic sectors. Complete hydrofluorocarbons and perfluorinated compound data were not available-for and so were omitted; they contribute to less than $1 \%$ of global warming. These data are divided by value of production for each sector to give the emissions coefficients of production using:

$$
B_{k}=E_{k} / X_{k}
$$

where $B_{k}$ is the vector of emissions coefficients of production for country $k\left(\mathrm{kgCO}_{2}-\mathrm{eq} / €\right)$; $E_{k}$ is the vector of sectoral emissions for country $k\left(\mathrm{kgCO}_{2}\right.$-eq); and $X_{k}$ is the vector of value of sectoral production for country $k(\epsilon)$.

IO tables for 1995 from the Organisation for Economic Cooperation and Development (2001) are used for each country and NACE sectors and, aggregated to match emissions sectors reported by Eurostat; this is the closest year to 1999 for which tables are available. Data are in national currency and \$ equivalents, converted to Euro using historic exchange rates and inflated to 1999 prices. The aggregated IO tables were used to generate production coefficients from Eqs. (2) and (3). 
$a_{i, j}=X_{i, j} / X_{j}$

where $a_{i, j}$ is an element of the national matrix of production coefficients representing the use of good $i$ in the production of $\operatorname{good} j(€) ; X_{i, j}$ is an element of the IO matrix $(€ / \epsilon)$; and $X_{j}$ is the production of $\operatorname{good} j(\epsilon)$.

$$
L_{k}=\left(I-A_{k}\right)^{-1}
$$

where $L_{k}$ is the Leontief inverse matrix for country $k(€ / €) ; I$ is the identity matrix; and $A_{k}$ is the matrix of production coefficients for country $k(€ / \epsilon)$.

The Leontief inverse matrix $\left(L_{k}\right)$ was then multiplied by the vector of emissions coefficients of production $\left(B_{k}\right)$ to give the vector of emissions coefficients of consumption $\left(M_{k}\right)$ using the equation:

$$
M_{k}=B_{k} \times L_{k}
$$

where $B_{k}$ is the vector of emissions coefficients of production for country $k\left(\mathrm{kgCO}_{2}\right.$-eq/€); and $M_{k}$ is the vector of emissions coefficients of consumption for country $k\left(\mathrm{kgCO}_{2}-\mathrm{eq} / €\right)$.

The 1999 cost of food in each of the countries was estimated by calculating the average per-capita expenditure on food, alcohol and tobacco (the latter could not be disaggregated and omitted, but represented less than $3 \%$ of expenditure in the countries studied) using household expenditure data and average household occupancies as reported by the Eurostat Household Budget Survey. These results were divided by the average individual food energy requirements (in kJ) for 1999-2001 obtained from UN Food and Agriculture Organisation's 2009 Statistical Yearbook to give the cost of one unit of food energy (see Eq. (5)). Food energy requirements vary within and between national populations; in Germany, for example, a 1998 study of individual food energy intake over 3 days recoded a mean of $8.96 \mathrm{MJ}$ with a standard deviation of $3.23 \mathrm{MJ}$ (Mensink et al., 2001); average values, however, were adopted.

$$
E f_{k}=E x_{k} / C_{k}
$$

where $E f_{k}$ is the food energy intensity of expenditure for country $k(€ / \mathrm{kJ}) . E x_{k}$ is the average daily per-capita expenditure on food products in country $k(\epsilon)$; and $C_{k}$ is the average daily per-capita consumption of food energy in country $k(\mathrm{~kJ})$.

Food energy requirements (FERs) for levels of activity associated with modes of transport were then calculated on a per passenger-kilometre basis. Representative METs for walking, cycling, using public transport and driving were obtained from The Compendium of Physical Activities Tracking Guide (Ainsworth et al., 2011). Although representative METs were used, they can vary significantly depending on exercise intensity; for example, METs can range from 4 to $16 \mathrm{kcal} / \mathrm{kg} / \mathrm{h}$ for leisurely and fast (>32 km/h) cycling; normal walking METs are in the range $3-6 \mathrm{kcal} / \mathrm{kg} / \mathrm{h}$. The MET in excess of the RMR (denoted $\mathrm{MET}^{\prime}$ ) was calculated by converting to SI units $(\mathrm{kJ} / \mathrm{kg} / \mathrm{h})$ and dividing by representative modal speeds to give food energy requirements per kilogram of body mass per passenger kilometre (Table 1 ).

Passenger-kilometre MET values are then multiplied by average body weights for each of the countries using Eurobarometer data (European Commission, 2006) to estimate the food energy requirements per passenger kilometre for each transport mode considered (Eq. (6)). These are multiplied by the emissions coefficients of consumption for the food, alcohol and tobacco sector calculated in Eq. (4) to give modal emissions intensities (Eq. (7)).

$$
F E R_{m, k}=M E T_{m}^{\prime} \times W_{k}
$$

where $F E R_{m, k}$ is the average food energy requirement for mode $m$ in country $k\left(\mathrm{~kJ} /\right.$ pass.km); $M E T_{m}^{\prime}$ is the average metabolic equivalent in excess of the resting metabolic rate for mode $m(\mathrm{~kJ} / \mathrm{kg} / \mathrm{pass} . \mathrm{km})$; and $W_{k}$ is the average weight of a person in country $k(\mathrm{~kg})$.

$$
E I_{m, k}=F E R_{m, k} \times E f_{k} \times M_{f, k}
$$

where $E I_{m, k}$ is the average food-related emissions intensity of mode $m$ in country $k\left(\mathrm{kgCO}_{2}\right.$-eq/pass.km); and $M_{f, k}$ is the food êmissions coefficient of consumption for country $k\left(\mathrm{kgCO}_{2}-\mathrm{eq} / €\right)$.

\section{Results}

Fig. 1 shows the GHG emissions intensities of consumption for the countries that vary from approximately 400 to 700 $\mathrm{gCO}_{2}$-eq/€; i.e. for every Euro spent on food, alcohol and tobacco in 1999 in the ten countries studied, between 400 and $700 \mathrm{~g}$ of greenhouse gases (normalised to the warming potential of $\mathrm{CO}_{2}$ ) were emitted. Denmark's high emissions coefficient is due to the structure of the country's agri-food industry - for example, the relatively large sizes of its livestock and food processing sectors (Eurostat, 2008). The indirect effect of France's low emissions intensities of electricity production on all economic sectors is an important contributing factor to its low emissions intensity of food consumption.

Fig. 2 shows the food energy requirements (FERs) per passenger kilometre for walking, cycling and driving. Passengers in cars, buses, trains and other self-propelled vehicles are omitted since they consume no more energy than if resting, so the over-and-above activity-related emissions cost is zero. It can be seen that for every passenger kilometre travelled, the average biochemical food energy requirements (as opposed to non-food energy requirements from fossil fuels) for an individual varies from approximately $230 \mathrm{~kJ} /$ pass.km for walking, to $90 \mathrm{~kJ} /$ pass.km for cycling and $15 \mathrm{~kJ} /$ pass.km for driving. Cycling is the most food energy-efficient form of active transport. 


\section{A. Duffy, R. Crawford/Transportation Research Part D xxx (2012) $x x x-x x x$}

Table 1

Metabolic equivalents and metabolic equivalents in excess of the resting metabolic rate for levels of effort associated with modal activities, representative speeds and associated MET's per passenger-kilometre.

\begin{tabular}{|c|c|c|c|c|c|c|}
\hline Mode & Description & $\begin{array}{l}\text { MET } \\
(\mathrm{kcal} / \mathrm{kg} / \mathrm{h})\end{array}$ & $\begin{array}{l}\mathrm{MET}^{\prime} \\
\text { (kcal/kg/h) }\end{array}$ & $\begin{array}{l}\mathrm{MET}^{\prime} \\
(\mathrm{kJ} / \mathrm{kg} / \mathrm{h})\end{array}$ & $\begin{array}{l}\text { Representative } \\
\text { speed }(\mathrm{km} / \mathrm{h})\end{array}$ & $\begin{array}{l}\mathrm{MET}^{\prime} \\
(\mathrm{kJ} / \mathrm{kg} / \text { pass.km) }\end{array}$ \\
\hline Walking & Walking to work or class & $4^{\mathrm{a}}$ & 3 & 12.56 & $4.0^{\mathrm{b}}$ & 3.14 \\
\hline Cycling & Bicycling, general & $7^{a}$ & 6 & 25.12 & $19.7^{\mathrm{c}}$ & 1.27 \\
\hline Public Transport & Riding a bus & $1^{\mathrm{a}}$ & 0 & 0.00 & $20^{\mathrm{d}}$ & 0.00 \\
\hline Driving & Automobile or light truck (not a semi) driving & $2^{\mathrm{a}}$ & 1 & 4.19 & $20^{\mathrm{d}}$ & 0.21 \\
\hline
\end{tabular}

a Ainsworth et al. (2011).

b Knoblauch et al. (2007).

c Dill (2009).

d André and Hammarström (2000).

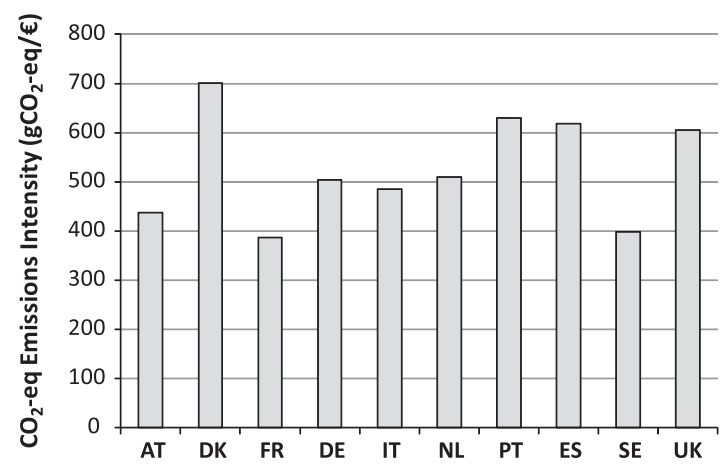

Fig. 1. Emissions coefficients of food, alcohol and tobacco consumption for the countries studied.

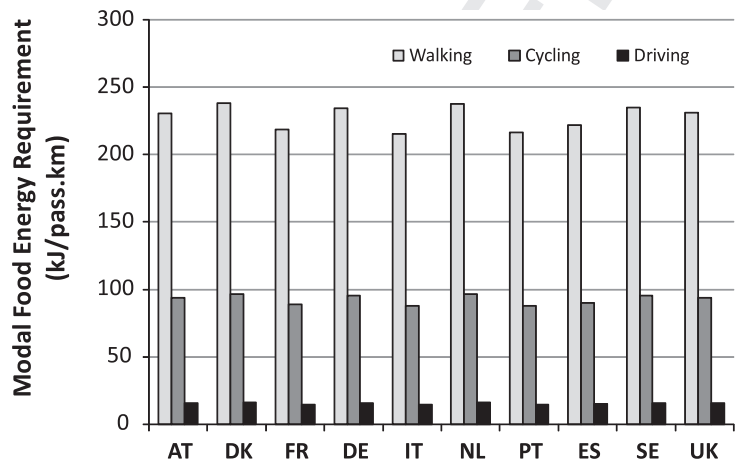

Fig. 2. Average food energy requirements (FERs) for each transport mode for the selected countries.

There is little variation between countries for each mode because the metabolic equivalent in excess of resting $\left(\mathrm{MET}^{\prime}\right)$ for each mode is the same for each country (assuming the same average metabolic response of their populations to activity) and there is little variation in average weights; these variables determine FER (see Eq. (6)).

Fig. 3 shows the food-related emissions intensities (EIs) for each mode of transport in the selected countries. This indicates the amount of carbon dioxide equivalent which is emitted as a result of food production when an average person travels a unit distance by a particular mode of transport ${ }^{1}$. It can be seen that due to the higher food energy requirements of walking this mode consistently results in higher emissions relative to cycling and driving. Denmark has the highest EIs for three main reasons: the relatively high cost of food, alcohol and tobacco $(0.46 € / \mathrm{MJ}$ compared to an average of $0.33 € / \mathrm{MJ})$; a high sector emissions intensity of consumption ( $701 \mathrm{gCO}_{2}$-eq/€ compared to an average of $528 \mathrm{gCO}_{2}$-eq/€, Fig. 2); and, to a lesser extent,

\footnotetext{
${ }^{1}$ I-O analysis assumes that the inputs to each economic sector are proportional to their outputs. Here it is assumed that energy use and GHG emissions are directly proportional to economic output. However, economies of scale may result in lower marginal fuel consumption and emissions. Hence, for example, if food consumption decreases due to an increase in a population's average fitness and corresponding decrease in weight, emissions may not decrease proportionately.
} 


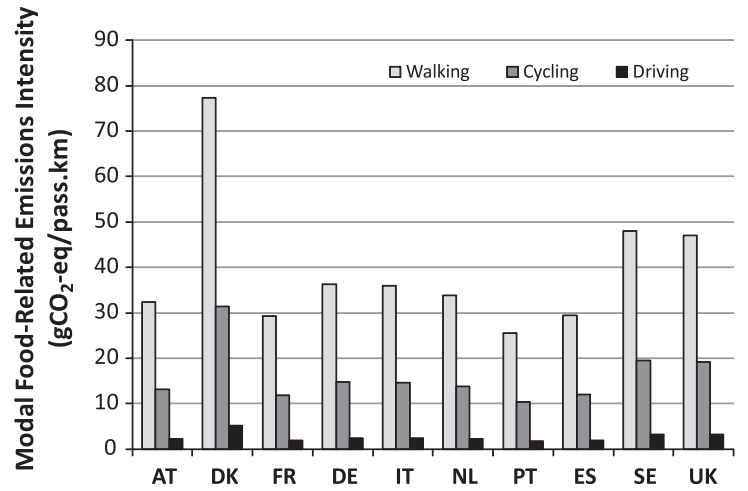

Fig. 3. Modal food-related emissions intensities for the selected countries.

a relatively high average weight. Portugal, Spain and France all have relatively low Els - the Iberian countries due largely to their low cost of food, alcohol and tobacco and France due to its low sector emissions intensity of consumption (Fig. 1) and moderate food costs.

The modal food-related emissions intensity of $41.8 \mathrm{gCO}_{2}$-eq/pass.km reported by Coley (2002) for walking falls within the range of emissions intensities identified in this study (25.6-77.3 $\mathrm{gCO}_{2}$-eq/pass.km) and is similar to the national results obtained for the UK. A country comparison cannot be made since Coley's study combined UK and Dutch data. The modal food-related emissions intensity for cycling of $30.43 \mathrm{gCO}_{2}$-eq/pass.km reported by Coley is at the upper range of the values estimated in this study (10.4-31.4 $\mathrm{gCO}_{2}$-eq/pass.km) and is 109\% and 59\% higher than Dutch and UK results. These difference may be explained by the fact that the Coley study used food energy intensities estimated using hybrid analysis where incomplete process data may have been employed. Furthermore, it uses 1986 nutritional data, 1993 process data and 1992 incomes; these older data result in lower emissions intensities.

The results are averaged across the adult population and do not consider individual groups of commuters who normally walk, cycle or drive due to a lack of suitable data. It is possible that some parameters affecting food-related modal emissions intensities would be different for these groups. For example, the dietary habits of people choosing active transport modes may differ from others, perhaps involving greater carbohydrate and lower protein contents. The weights and, consequently, METs of active, fit individuals may also be lower resulting in lower emissions. Finally, although a positive correlation between exercise and caloric intake is reported in medical literature, the extent to which walkers and cyclists consume more calories than drivers is not known. A relatively carbohydrate-rich diet, lower body mass and a weak correlation between exercise and calorie intake would all reduce the emissions intensities of walking and cycling.

UK data is used to illustrate the relative life cycle contributions of food-related emissions for four modes of transport: private car, bus, bicycle and walking. Through necessity a variety of data sources employing different collection methods were used for each mode leading to some relative error. 1999 was taken as the base year to tie in with the analysis above. The boundary included emissions associated with: manufacture; operational fuel and maintenance requirements; food-energy requirements; and disposal; results were expressed as $\mathrm{CO}_{2}$-eq/pass.km. Road maintenance costs are excluded since it is HGVs which cause most damage to the road network. Fuel emissions were estimated by dividing car and bus emissions by passenger kilometres using UK Department for Transport data. Manufacturing and non-fuel (maintenance, insurance and taxation) emissions were typically estimated by multiplying costs (from a variety of sources) by emissions factors for the relevant IO sector.

For cars, 1999 fuel-related GHG emissions, distance travelled and average occupancy data were obtained from the Department for Transport's Transport Statistics Great Britain (2010) to give emissions per passenger kilometre. The Automobile Association' (1999) Archive of Running Costs provided non-fuel (maintenance, taxation and insurance) costs which were combined with the IO-derived emissions intensity of the appropriate sector determined as previously explained to give emissions per passenger kilometre. Indirect emissions associated with car production were determined using IO analysis by multiplying the average 1999 cost of a car in the UK $(€ 22,149)$ by the sectoral emissions intensity for the manufacture of motor vehicles $\left(715 \mathrm{gCO}_{2} \mathrm{eq} / €\right)$ and dividing by distance travelled, average occupancy (Department for Transport, 2010) and a car life expectancy of 13.5 years; this resulted in estimated production emissions of $32.9 \mathrm{gCO}_{2}$-eq/pass.km. Disposal emissions were ignored as negligible given the fact that most car components are recycled and are therefore low compared to life cycle emissions. An emission factor of $205.5 \mathrm{gCO}_{2}$-eq/pass.km was estimated, dominated by fuel use (63\%) followed by non-fuel emissions (19\%), manufacture and disposal (16\%) with very low food-related emissions (2\%).

For buses, 1999 fuel-related GHG emissions and passenger kilometres distance travelled are obtained from Department for Transport (2010) to give emissions per passenger kilometre, and maintenance costs from Department for Transport (Department for Transport, 2011a) using an average speed of $20 \mathrm{~km} / \mathrm{h}$ divided by average occupancy data from the Bus Statistics database (Department for Transport, 2011b); sector emîssions intensities are used to estimate related emissions. The manufacturing and disposal emissions intensity of $32.9 \mathrm{gCO}_{2}$-eq/pass. $\mathrm{km}$ for cars was applied in the absence of reliable data. 
Table 2

Costs of life cycle stages for modes in €/veh.km (1999 prices).

\begin{tabular}{llll}
\hline Life cycle stage & Car travel & Bus travel & Walking \\
\hline Manufacture & n/a & n/a & 0.030 \\
Non-fuel operation and maintenance & $0.154^{\mathrm{a}}$ & $0.834^{\mathrm{b}}$ & 0.073 \\
neg. & 0.093 & \\
\hline
\end{tabular}

a Automobile Association (1999) with an exchange rate of $0.65 £ / €$ - assumes an engine size of 1401-2000 cc.

b Department for Transport (2011a).

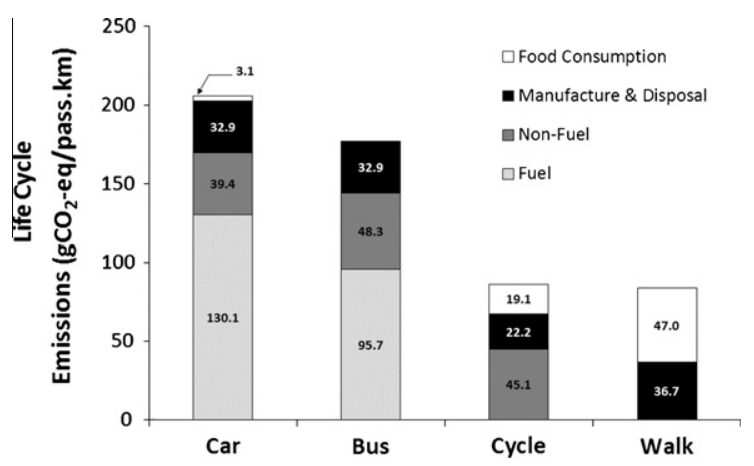

Fig. 4. Life cycle GHG emissions by transport mode for the UK.

Food energy emissions for bus passengers are assumed to be zero since passengers are resting and because the driver's emissions, when divided among the passengers, are negligible (less than $0.5 \mathrm{gCO}_{2}$-eq/pass.km). A modal emissions intensity of $176.9 \mathrm{gCO}_{2}$-eq/pass.km is estimated; fuel-related emissions accounted for $54 \%$ of emissions, non-fuel for $27 \%$ and manufacture and disposal for $19 \%$.

Cycling does not incur fossil fuel-related operational emissions. Average prices for the purchase and annual maintenance of bicycles were obtained from cycling stores and deflated to 1999 prices. Average annual distance travelled by cyclists was obtained from the National Travel Survey 2009 (Department for Transport, 2009); this, together with sectoral emissions intensities are applied to estimate emissions per passenger kilometre cycled. An estimated $86.4 \mathrm{gCO}_{2}$-eq $/$ pass.km was emitted by cyclists in 1999, dominated by maintenance emissions (52\%), followed by manufacture (26\%) and food energy (22\%).

Walking emissions are sensitive to the purchase of footwear and annual distance travelled. Two assumptions may be made: an 'occasional' walker who does not purchase additional footwear for walking; and a 'dedicated' walker who will require additional footwear due to their modal choice. Emissions for the former are food-related only. The analysis here focuses on the latter where it is assumed that $880 \mathrm{~km}$ are walked annually (equivalent to a daily commute of $2 \mathrm{~km}$ to and from work for 220 days of the year). A single pair of walking shoes (valued at $€ 64$ in 1999) is used per annum. A sector emissions factor is applied to estimate emissions per passenger kilometre. Indirect shoe manufacturing emissions account for about $43 \%$ of emissions of $83.7 \mathrm{gCO}_{2}$-eq/pass.km for walking, with food accounting for the balance. Table 2 summarises the non-fuel operational costs used.

Fig. 4 shows the comparative GHG emissions for each of the modes examined. Car travel has the highest emissions intensity, followed by bus travel, cycling, and walking. Bus emissions are elevated by their low average occupancy levels. Cycling and, to a greater extent, walking emissions are significantly affected by food-energy emissions. Despite the lower emissions associated with food energy requirements and manufacture for cycling, walking results in slightly lower overall emissions due to the substantial emissions resulting from bicycle maintenance.

\section{Conclusions}

A life cycle assessment of modal emissions in the UK was undertaken using the food-energy emissions intensities estimated. Car travel was found to have the highest emissions intensity, followed by bus travel, cycling and walking. Car, and to a lesser extent, bus emissions are dominated by operational fuel use. Cycling and, to a greater extent, walking emissions are significantly affected by food-energy emissions, accounting for $22 \%$ and $56 \%$ of modal emissions. Walking results in the lowest overall emissions.

\section{Uncited reference}

Treloar et al. (2000). 


\section{References}

Automobile Association, 1999. Motoring Costs 1999, Petrol Cars. Automobile Association. <http://www.theaa.com/motoring_advice/running_costs/> (accessed 25.05.11).

Ainsworth, B.E., Haskell, W.L., Herrmann, S.D., Meckes, N., Bassett Jr., D.R., Tudor-Locke, C., Greer, J.L., Vezina, J., Whitt-Glover, M.C., Leon, A.S., 2011. The Compendium of Physical Activities Tracking Guide. Lifestyles Research Center, College of Nursing \& Health Innovation, Arizona State University.

André, M., Hammarström, U., 2000. Driving speeds in Europe for pollutant emissions estimation. Transportation Research D 5, 321-335.

Chapman, L., 2007. Transport and climate change: a review. Journal of Transport Geography 15, 354-367.

Coley, D., 2002. Emission factors for human activity. Energy Policy 30 (1), 3-5, ISSN:0301-4215, 10.1016/S0301-4215(01)00061-1.

Department for Transport, 2009. National Travel Survey: 2009. Department for Transport, London.

Department for Transport, 2010. Transport Statistics Great Britain: 2010. Department for Transport, London.

Department for Transport, 2011a. Transport Analysis Guidance (TAG) - Values of Time and Operating Costs. Department for Transport, London.

Department for Transport, 2011b. Bus Statistics BUS0302 and BUS0207. Department for Transport, London.

Dill, J., 2009. Bicycling for transportation and health: the role of infrastructure. Journal of Public Health Policy 30, S95-S110.

European Commission, 2006. Health and Food - Special Eurobarometer 246/Wave 64.3. European Commission, Brussels.

Eurostat, 2008. Food: From Farm to Fork Statistics, 2008 Edition. Eurostat Pocketbooks, European Commission.

Forster, P., Ramaswamy, V., Artaxo, P., Berntsen, T., Betts, R., Fahey, D., Haywood, J., Lean, J., Lowe, D., Myhre, G., Nganga, J., Prinn, R., Raga, G., Schulz, M., Van Dorland, R., 2007. Changes in Atmospheric Constituents and in Radiative Forcing. In: Solomon, S., Qin, D., Manning, M., Chen, Z., Marquis, M., Averyt, K.B., Tignor, M., Miller, H.L. (Eds.), Climate Change 2007: The Physical Science Basis. Contribution of Working Group I to the 4th Assessment Report of the Intergovernmental Panel on Climate Change. Cambridge University Press, Cambridge.

Knoblauch, R., Pietrucha, M., Nitzburg, M., 2007. Field studies of pedestrian walking speed and start-up time. Transportation Research Record 1538, 27-38. Longo, D., Fauci, A., Kasper, D., Hauser, S., Jameson, J., Loscalzo, J., 2011. Harrison's Principles of Internal Medicine, 18th ed. McGraw Hill, New York.

Mensink, G., Haftenberger, M., Thamm, M., 2001. Validity of DISHES 98, a computerised dietary history interview: energy and macronutrient intake. European Journal of Clinical Nutrition 55, 409-417.

McArdle, W., Katch, F., Katch, V., 2007. Exercise Physiology: Energy, Nutrition, and Human Performance. Lippincott Williams \& Wilkins, Philadelphia.

Organisation for Economic Cooperation and Development, 2001. OECD Economic Outlook, vol. 2001/2, no. 70 December, OECD, Paris.

Santos, G., Behrendt, H., Teytelboym, A., 2010. Part II: Policy instruments for sustainable road transport. Research in Transportation Economics $28,46-91$.

Treloar, G., Fay, R., Love, P., Iyer-Raniga, U., 2000. Analysing the life-cycle energy of an Australian residential building and its householders. Building Research and Information 28, 184195.

van Engelenburg, B., van Rossum, T., Blok, K., Vringer, K., 1994. Calculating the energy requirements of household purchases, a practical step by step method. Energy Policy 22, 618-656.

Walsh, C., Jakeman, P., Moles, R., O'Regan, B., 2008. A comparison of carbon dioxide emissions associated with motorised transport modes and cycling in Ireland. Transportation Research D 13, 392-399. 